UDC 621.385.6

\author{
A. A. Kurayev, V. V. Matveyenko, T. L. Popkova \\ Belarusian State University of Informatics and Radioelectronics \\ 6, P. Brovki St., Minsk 220013, Belarus \\ E-mail: vladzimir66@bsuir.by
}

\title{
ALGORITHMS WITH STABILIZING COEFFICIENTS FOR SOLVING POORLY DETERMINED RADIOPHYSICS PROBLEMS
}

This article describes the algorithms with correcting and stabilizing coefficients to provide sustainable solutions to systems of equations related to poorly determined tasks of electrodynamics and nonlinear dynamics. It demonstrates the use of the modified algorithms in the task of $E_{0 i}$-waves propagation in irregular waveguide and dynamic model of Rössler's chaos. In the latter case the article demonstrates that "deterministic" (i. e. regenerating) chaos is impossible. Fig. 5. Ref.: 6 title.

Key words: poorly determined task, stable numerical method, supercritical waves in waveguide, dynamic chaos.

There is a wide class of poorly determined or incorrectly formulated tasks in both electrodynamics and nonlinear dynamics. For example, in electrodynamics there are tasks of calculating the supercritical or partial (irregular structures) waveguide supercritical waves, in nonlinear dynamics there are dynamic (“deterministic") chaos modes in oscillatory systems. In the first case, an arbitrarily small calculation errors or initial conditions lead to an exponential error, i. e. to the divergence of the solution [1, 2]. In the second case, an arbitrarily small calculation errors lead to their accumulation and to attractor malfunction so appears "strange attractor" [3]. It should be noted that "strange attractor" in real structures described by these models appears actually. But here its "actuation" is produced by natural noises in physical systems, rather than "numerical noise" of numerical model, where chaos has indeed "deterministic" nature.

The article suggests several modifications for "numerical noise" elimination to ensure the sustainability of solutions in relation to calculation errors.

1. $E_{0 i}$-wave propagation in irregular waveguide with circular cross-section. The theory of wave propagation in irregular waveguides based on the method of coordinate transformation and projection method leads in the end to double point boundary-value problem for system of ordinary differential equations (ODE) in relation to the amplitudes of coupled normal waves in a transformed coordinate system [1]. ODE for irregular waveguide with circular cross-section is divided into $\mathrm{H}_{0 i^{-}}$and $E_{0 i}$-waves (zero-azimuth index waves), i. e. $H_{0 i^{-}}$and $E_{0 i}$-waves systems become independent [1]. Thus, excitation problems are solved independently for $H_{0 i}$ and $E_{0 i}$-modes.

The proposed article uses (for formulation of excitation equation $E_{0 i}$-waves) suitable approach (from the point of view of the above considerations
[4, 5]): $\vec{E}^{\prime}$ is excluded in the transformed system and the equation of the second order is solved for $\vec{H}^{\prime}$. After such an approach the boundary value $E_{0 i}$-waves problem becomes a scalar $\left(\vec{H}^{\prime}\right.$ has only one component $\mathrm{pH}_{\varphi}^{\prime}$ ), and the resulting ODE system relative to normal waves amplitude is transformed to even form. The demonstrated examples of numerical solution of $E_{0 i}$-waves tasks allow illustrating the stability of numerical algorithms for solving ODE system received for $E_{0 i}$-waves.

It is important to emphasize the relevance of equation formulation for $E_{0 i}$-waves excitation in irregular waveguides with a circular cross-section in adequate form for stable numerical methods, as these types of waves are used in superpowerful Cherenkov's amplifiers and generators ensuring the creation of radar systems and anti-ballistic missile systems of new generation.

Here we consider the longitudinally-irregular waveguide with circular cross-section, internal border set as $b(z), b$ is the waveguide radius, $z$ is the longitudinal coordinate. Boundary condition on a perfectly conductive inner surface $b(z)$ is specified as $[\vec{n} \vec{E}]_{r=b(z)}=0$.

After a coordinate transformation (moving from real coordinate system $r, \varphi, z$ to $\rho, \varphi, z$, where $\rho=r / b(z)$ ), get the boundary condition (1)

$\left[\vec{n} \vec{E}^{\prime}\right]_{\rho=1}=0$,

then Maxwell's equations are the following form (vacuum medium) [1, 5]:

$\operatorname{rot} \vec{H}^{\prime}=\varepsilon_{0} \hat{g} \frac{\partial \vec{E}^{\prime}}{\partial t}+\hat{g} \vec{J}^{\prime}, \quad \operatorname{rot} \vec{E}^{\prime}=-\mu_{0} \hat{g} \frac{\partial \vec{H}^{\prime}}{\partial t}$.

Here $\varepsilon_{0}, \mu_{0}$ are the dielectric and magnetic permeability of vacuum accordingly, and auxiliary vector components $\vec{E}^{\prime}, \vec{H}^{\prime}, \vec{J}^{\prime}$ this way are associated with covariant vectors $\vec{E}, \vec{H}, \vec{J}$ (physical 
vectors of electric and magnetic fields and electric current density) $[1,4,5]$ :

$\vec{E}=E_{\rho}^{\prime} \vec{a}^{1}+E_{\varphi}^{\prime} \rho \vec{a}^{2}+E_{z}^{\prime} \vec{a}^{3}$,

$\vec{H}=H_{\rho}^{\prime} \vec{a}^{1}+H_{\varphi}^{\prime} \rho \vec{a}^{2}+H_{z}^{\prime} \vec{a}^{3}$,

$\vec{J}=J_{\rho}^{\prime} \vec{a}^{1}+J_{\varphi}^{\prime} \rho \vec{a}^{2}+J_{z}^{\prime} \vec{a}^{3}$.

Where $\quad \vec{a}^{1}, \vec{a}^{2}, \vec{a}^{3} \quad$ are reciprocal unorthogonal coordinate system vectors $\rho, \varphi, z$ : $\vec{a}^{1}=\frac{\vec{r}_{0}}{b}-\vec{z} \frac{\rho}{b} \frac{d b}{d z}, \quad \vec{a}^{2}=\frac{\vec{\varphi}_{0}}{b \rho}, \quad \vec{a}^{3}=\vec{z}_{0}$

Covariant tensor $\hat{g}$ is $[1,5]$ :

$$
\begin{aligned}
& \hat{g}=\left(\begin{array}{ccc}
g_{11} & 0 & g_{13} \\
0 & 1 & 0 \\
g_{31} & 0 & g_{33}
\end{array}\right) \\
& g_{11}=1+\rho^{2}\left(\frac{d b}{d z}\right)^{2}, g_{13}=g_{31}=-\rho b \frac{d b}{d z}, g_{33}=b^{2} .
\end{aligned}
$$

Contravariant tensor $\hat{g}^{-1}$ is

$$
\begin{aligned}
& \hat{g}^{-1}=\left(\begin{array}{ccc}
1 & 0 & G_{13} \\
0 & 0 & 0 \\
G_{31} & 0 & G_{33}
\end{array}\right), \\
& G_{13}=G_{31}=\frac{\rho}{b} \frac{d b}{d z}, G_{33}=\frac{1}{b^{2}} \frac{\rho^{2}}{b^{2}}\left(\frac{d b}{d z}\right)^{2} .
\end{aligned}
$$

Now eliminate from the system (3) $\vec{E}^{\prime}$ then get the equation for $\vec{H}^{\prime}$ :

$$
\operatorname{rot}\left(\hat{g}^{-1} \operatorname{rot} \vec{H}^{\prime}\right)-\varepsilon_{0} \mu_{0} \frac{\partial^{2}}{\partial t^{2}}\left(\hat{g} \vec{H}^{\prime}\right)-\operatorname{rot} \vec{J}^{\prime}=0 \text {. }
$$

Believing that the process is periodic and established (stationary modes of relativistic TWT and BWT) can present the solution $\vec{H}^{\prime}$ in the form of

$$
\vec{H}^{\prime}=\operatorname{Re} \sum_{m=0}^{M} \dot{\vec{H}}_{m}^{\prime} e^{j m \omega t} \text {. }
$$

Now return to the item of $E_{0 j}$-wave excitation in the waveguide. Then taking into account boundary condition (2) $\dot{\vec{H}}_{m}^{\prime}$ can be represented as the next finite series $[1,4,5]$ :

$$
\begin{aligned}
& \dot{\vec{H}}_{m}^{\prime}=\sum_{i=1}^{I} \dot{A}_{m i}^{M}(z) \vec{\varphi}_{0} J_{1}\left(v_{0 i} \rho\right), \\
& J_{0}\left(v_{0 i}\right)=0, \quad i=1,2, \ldots
\end{aligned}
$$

For getting the ODE system finding $E_{0 j}$ associated normal wave amplitudes will take advantage of projection Galerkin's method. Substitute solution (7), (8) in the source system (6) and replace its equivalent projection system of equations:

$$
\begin{aligned}
& \frac{1}{2 \pi} \int_{0}^{2 \pi} \int_{0}\left\{\operatorname{rot}\left(\hat{g}^{-1} \operatorname{rot} \vec{H}^{\prime}\right)-\varepsilon_{0} \mu_{0} \frac{\partial^{2}}{\partial t^{2}}\left(\hat{g} \vec{H}^{\prime}\right)\right\} \times \\
& \times \vec{\varphi}_{0} J_{1}\left(v_{0 p} \rho\right) \rho d \rho d(\omega t)= \\
& =\frac{1}{2 \pi} \int_{0}^{2 \pi} \int_{0}^{1} \operatorname{rot} \vec{J}^{\prime} \vec{\varphi}_{0} J_{1}\left(v_{0 p} \rho\right) \rho d \rho d(\omega t) ;
\end{aligned}
$$

$\int_{0}^{1}\left\{\operatorname{rot}\left(\hat{g}^{-1} \operatorname{rot} \dot{\vec{H}}_{m}^{\prime}\right)+m^{2} \omega^{2} \varepsilon_{0} \mu_{0}\left(\hat{g} \dot{\vec{H}}_{m}^{\prime}\right)\right\} \times$

$\times \vec{\varphi}_{0} J_{1}\left(v_{0 p} \rho\right) \rho d \rho=$

$=\frac{1}{2 \pi} \int_{0}^{2 \pi} \int_{0}^{1} \operatorname{rot} \vec{J}^{\prime} \vec{\varphi}_{0} J_{1}\left(v_{0 p} \rho\right) \rho d \rho e^{-j m \omega t} d(\omega t) ;$

$\int_{0}^{1}\left\{\operatorname{rot}\left(\hat{\boldsymbol{g}}^{-1} \operatorname{rot} \dot{\overrightarrow{\vec{H}}}_{m}^{\prime}\right)+m^{2} \omega^{2} \varepsilon_{0} \mu_{0} \hat{\mathrm{g}} \dot{\vec{H}}_{m}^{\prime}\right\} \times$

$\times \vec{\varphi}_{0} J_{1}\left(v_{0 p} \rho\right) \rho d \rho=$

$=-\frac{1}{2 \pi} \times$

$\times \int_{0}^{2 \pi} \int_{0}^{1}\left(\frac{J_{z}^{\prime}}{\partial \rho}-\frac{J_{\rho}^{\prime}}{\partial z}\right) J_{1}\left(v_{0 p} \rho\right) \rho d \rho e^{-j m \omega t} d(\omega t)=$ $=-I_{m p}(z), \quad p=1,2, \ldots I, \quad m=1,2, \ldots M$.

After insert equations (8) taking into account (4), (5) into (9) for $\dot{\vec{H}}_{m}^{\prime}$ is ODE system to $\dot{A}_{m i}^{M}$ :

$$
\begin{aligned}
& \frac{d^{2} \dot{A}_{m p}^{M}}{d z^{2}}+\left(m^{2}-\frac{v_{0 p}^{2}}{b^{2}}\right) \dot{A}_{m p}^{M}+ \\
& +\frac{1}{h_{p p}} \sum_{i}^{I}\left\{-\frac{2}{b} \frac{d b}{d z} I_{1 p i} \frac{\dot{A}_{m i}^{M}}{d z}+\right. \\
& \left.+\dot{A}_{m i}^{M}\left[\left(\frac{3}{b^{2}}\left(\frac{d b}{d z}\right)^{2}+\frac{1}{b} \frac{d^{2} b}{d z^{2}}\right) I_{1 p i}-\frac{1}{b^{2}} \frac{d b}{d z} I_{3 i p}\right]\right\}= \\
& =I_{m p}(z) .
\end{aligned}
$$

Boundary condition for ODE system (10) matched on regular waveguide ends has the standard form [1].

The system (10), however, does not satisfy our task, because it contains the first derivative of $\dot{A}_{m i}^{M} \quad$ function that leads to instability of the computational algorithm. Therefore, we introduce the replacement: $\dot{A}_{m p}^{M}=b(z) \dot{C}_{m p}^{M}(z)$. Then ODE system has required even representation (the main part). Physical magnetic field intensity at $m \omega$ frequency is expressed as $\vec{H}_{m}=\vec{\varphi}_{0} \dot{H}_{m \varphi}$, where

$$
\dot{H}_{m \varphi}=\sum_{p=1}^{l} \dot{C}_{m p}^{M}(z) J_{1}\left(v_{0 p} \frac{r}{b(z)}\right) e^{i m \omega t} .
$$


And physical electric field intensity $\vec{E}_{m}$,

$\vec{E}_{m}=\frac{1}{i m \omega \varepsilon_{0}}\left\{\frac{\partial\left(r \dot{H}_{m \varphi}\right)}{r \partial r} \vec{z}_{0}-\frac{\partial \dot{H}_{m \varphi}}{\partial z} \vec{r}_{0}\right\}$,

here complex amplitude $\dot{C}_{m p}^{M}$ is used by the equation:

$\frac{d^{2} \dot{C}_{m p}^{M}}{d z^{2}}+\left(m^{2}-\frac{v_{0 p}^{2}}{b^{2}}+\frac{1}{b^{2}}\left(\frac{d b}{d z}\right)^{2}+\frac{2}{b} \frac{d^{2} b}{d z^{2}}-\right.$

$\left.-\frac{1}{b^{2}}\left(\frac{d b}{d z}\right) \frac{I_{3 p p}}{h_{p p}}\right) \dot{C}_{m p}^{M}+$

$+\sum_{k=1, p \neq k}^{l}\left\{-\frac{2}{b^{2}} \frac{d b}{d z} \frac{I_{1 k p}}{h_{p p}}\left(\frac{d b}{d z} \dot{C}_{m k}^{M}+b \frac{d \dot{C}_{m k}^{M}}{d z}\right)+\right.$

$+\dot{C}_{m k}^{M}\left[\left(\frac{3}{b^{2}}\left(\frac{d b}{d z}\right)^{2}+\frac{1}{b} \frac{d^{2} b}{d z^{2}}\right) \frac{I_{1 k p}}{h_{p p}}-\right.$

$\left.\left.-\frac{1}{b^{2}}\left(\frac{d b}{d z}\right) \frac{I_{3 k p}}{h_{p p}}\right]\right\}=0$.

Here are the following designations: $b(z)-$ profile waveguide; $v_{0 p}-p$ - root of the Bessel function $J_{0}(x)$ : $J_{0}\left(v_{0 p}\right)=0 ; h_{p p}=J_{1}^{2}\left(v_{0 p}\right) / 2 ; \rho=r / b(z)$.

$I_{1 k p}=\int_{0}^{1} J_{0}\left(v_{0 k} \rho\right) J_{1}\left(v_{0 p} \rho\right) v_{0 k} \rho^{2} d \rho$,

$I_{3 k p}=\int_{0}^{1} J_{1}\left(v_{0 k} \rho\right) J_{1}\left(v_{0 p} \rho\right)\left(v_{0 k} \rho\right)^{2} d \rho$.

Equations (11) and (12) are given in length units for $z, b(z)$. It is obvious that if the left and the right of these equations are multiplied by $1 / k^{2}=c^{2} / \omega^{2}$, that quantity $z, b(z)$ are converted into dimensionless, that obviously comfortable for making calculations. From this point on let us take designation of these values without modification that is for (11) and (12) equations $b(z) \equiv k b(z), z \equiv k z$.

The even form of excitation equations $E_{0 i}$-wave (12) opens the way to use even algorithms for step-by-step solution of these equations proposed in [5] and tested on solution of $H_{0 i}$-waves tasks [5].

Let us use step by step algorithm described in [5] of even equation solution for $H_{0 i}$-waves

$\frac{d^{2} \dot{C}}{d z^{2}}+Q(z) \dot{C}=\dot{f}$

in the following form:

$\dot{C}_{k+2}=\frac{2 \dot{C}_{k+1}}{\tau}-\frac{\dot{C}_{k}}{\tau^{2}}-\frac{\dot{C}_{k+1}}{\tau} h^{2} Q_{k+1}+h^{2} \frac{\dot{f}_{k+1}}{\tau^{2}}$,

where $\tau>1$ the number selected when specific calculations, at that $\tau \rightarrow 1$ when reducing integration step. Introduction to algorithm (14) parameter $\tau>1$ is caused necessity to ensure the uniqueness of solution of boundary-value problem for the equation (12): the decision must have the only field component excited by sources at the left end. Actually when using standard algorithms through very minute calculation errors appears backward field component which is not consistent with the physical meaning, which for supercritical modes increases exponentially in $+z$ direction, leading to a rapid solution collapse. Introduction of the parameter $\tau$ in algorithm excludes appearance of incorrect component and thus ensures the sustainability of stepby-step procedures for the calculation. Note that the introduction of the parameter $\tau$ is necessary to meet the conditions of the uniqueness of a solution theorem: the environment must have a place at least small losses.

The calculated waveguide profile $b(z)$ in Fig. 1, a, and in Fig. 1, b - distribution $\left|\dot{C}_{1 p}^{M}\right|$ when the number of steps for even algorithm $N=20000$. Acceptable accuracy is achieved when $N=2000$.

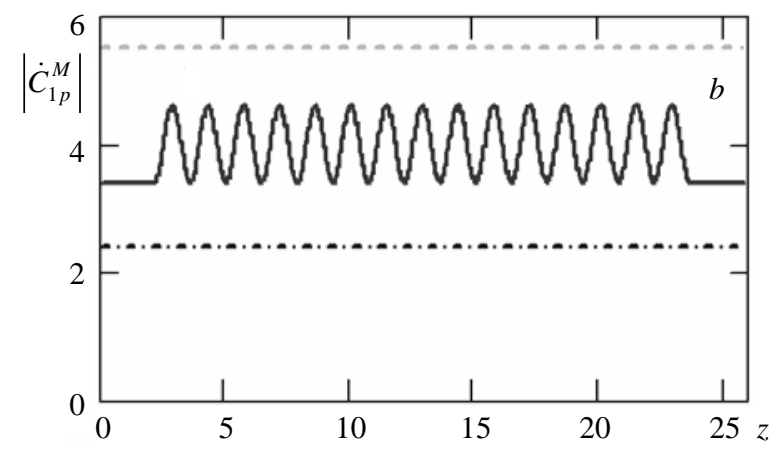

a)

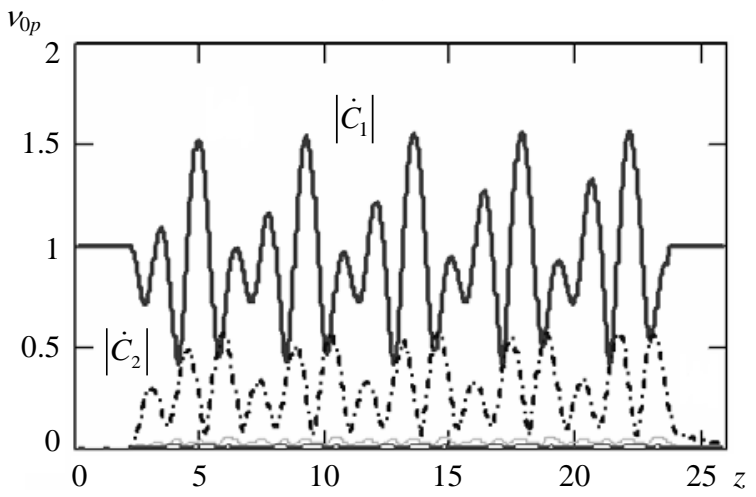

b)

Fig. 1. E-wave field calculation using an even algorithm: waveguide profile and $v_{0 p}$ : -.- $v_{01}$, --- $v_{02}$ (a); $\left|\dot{C}_{1 p}^{M}\right|(z)$ when $N=20000$ : $--p=1 ;-.-p=2 ;-p=3 ;--p=4$ (b)

Fig. 2 illustrates the convergence even algorithm when increasing $N$ : here are the dependences of maximum along $z$ for relative error $\delta\left|\dot{C}_{1 p}^{M}\right|$ and the dependences $1 / \tau_{p}$ from $N(p=1,2, \ldots)$. 


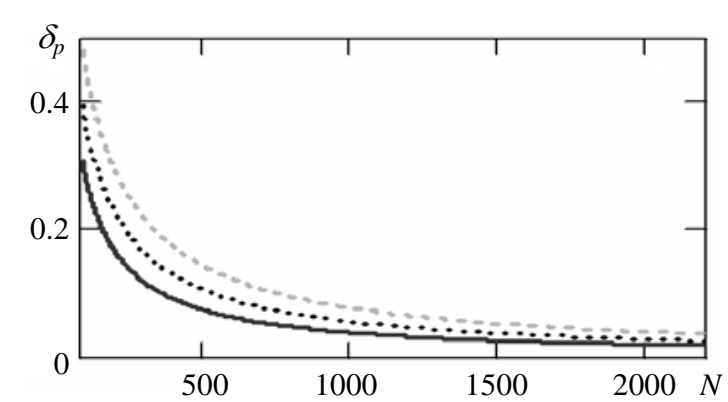

a)

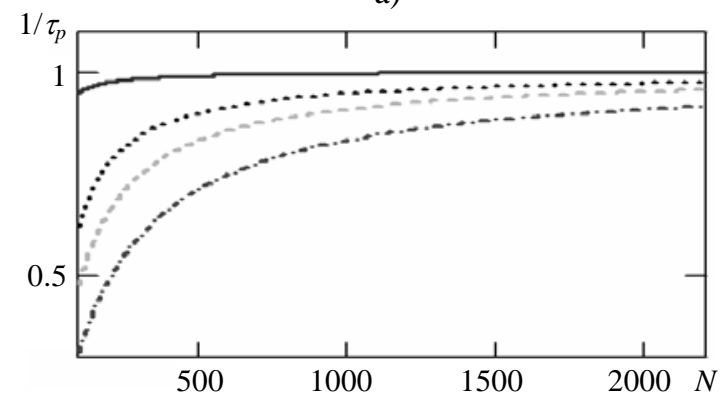

b)

Fig. 2. The convergence even algorithm when increasing $N$ : $\delta_{p}=\delta_{p}(N)(a) ; 1 / \tau_{p}(N) ;-p=1 ;--p=2 ;---p=3 ;-.-p=4$ (b)

Fig. 3 illustrates the effect of higher postcritical $E_{0 j}$-waves on the structure of the fields in the waveguide.

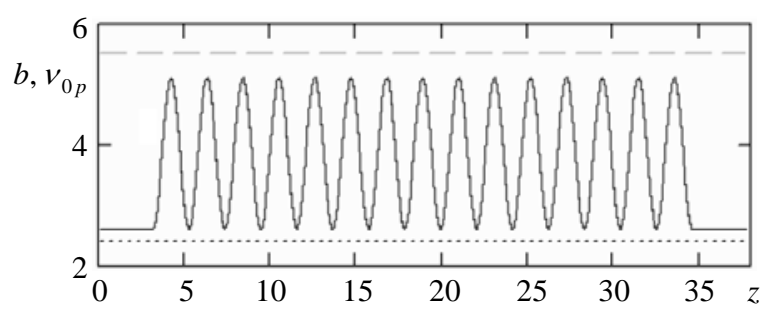

a)

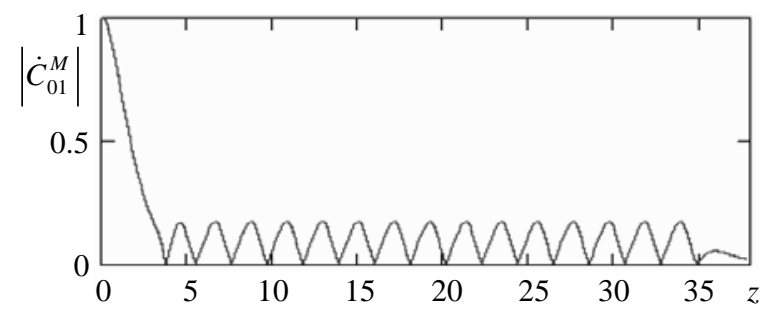

b)

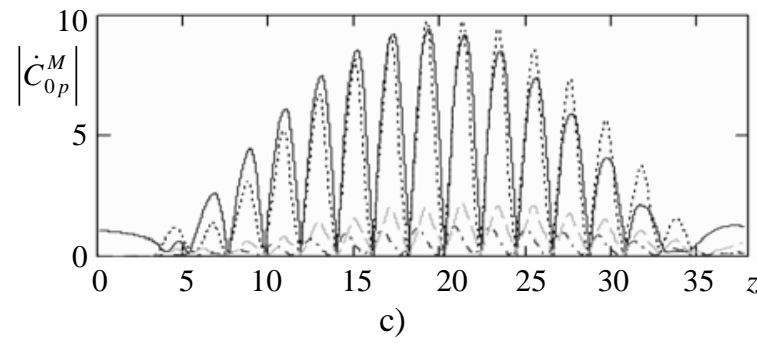

Fig. 3. Effect of higher postcritical $E_{02^{-}}, E_{03^{-}}, E_{04}$-waves on structure of fields in waveguide: waveguide profile $b(\mathrm{z})(\mathrm{a}) ;\left|\dot{C}_{01}^{M}\right|$ (b); mode composition of full field in waveguide: $-p=1 ;---p=2 ;--p=3$; $-\cdot-p=4$ (c)

\section{The elimination of exponential} calculation errors. Let us use recurrent calculation formula of exponential function $e^{\dot{A} t}(\dot{A}-$ a complex number) [2]:

$e^{\dot{A} \Delta n} \approx \frac{(2+\Delta \dot{A})^{n}}{(2-\Delta \dot{A})^{n}}$.

Here $t=\Delta n ; \Delta$ - step, $n$ - node number.

Let function $f(t)$ is calculated by using a simple one-step algorithm:

$$
\begin{aligned}
& f_{n+1}=f_{n}+\Delta f_{n}^{\prime}, \\
& f_{n+1} \equiv f\left(t_{n+1}\right)=f(\Delta(n+1)), f_{n} \equiv f\left(t_{n}\right)=f(\Delta n) .
\end{aligned}
$$

A simple numerical way to "separate from" the exponent with power $(\alpha t)$ can be illustrated by calculation example with formula (15) $\left(e^{\alpha t}-\right.$ "separate from” exponent):

$$
f_{n}=\frac{(2+\Delta \dot{A})}{(2-\Delta \dot{A})} f_{n-1}[1-\Delta \alpha]
$$

multiplicand $\beta=[1-\Delta \alpha]$ and provides a "separate from” exponent.

One of the most famous mathematical nonlinear dynamics models demonstrating the "deterministic chaos" is the Rössler's equation system [6]:

$$
\left\{\begin{array}{l}
\frac{d x}{d t}=-(y+z), \\
\frac{d y}{d t}=x+e y, \\
\frac{d z}{d t}=w-m z+x z .
\end{array}\right.
$$

Here $e, w, m$ - constant numbers, model parameters; $t$ - argument of the functions $x, y, z$.

Let us introduce the function

$$
\text { pif }=z_{k+1}^{2}-z_{k}^{2}-\left(z_{k+1}-z_{k}\right)\left(z_{k+1}+z_{k}\right) \text {. }
$$

This function determines a numerical residual of "energy" solution $z(t)$ and therefore is "numerical noise” indicator.

Solving the equation system (18) by the usual step-by-step methods in phase plane $x, y$ one gets the "strange attractor" and demonstrates "deterministic" i. e. regenerating chaos. Fig. 4 shows a similar solution with using IV order Runge-Kutta method at $e=w=0.2 ; \quad m=6.5 ; \quad \Delta=0.00042$, $n_{\max }=100000$. The same solution is obtained by using any other standard method - Adams, Hamming, Bimon, Werle, and others.

Note that pif-"surges" correlate with the occurrence of "peaks" when finding $z(t)$, that is an indicator of "attractor" malfunction in the plane $x, y$. 


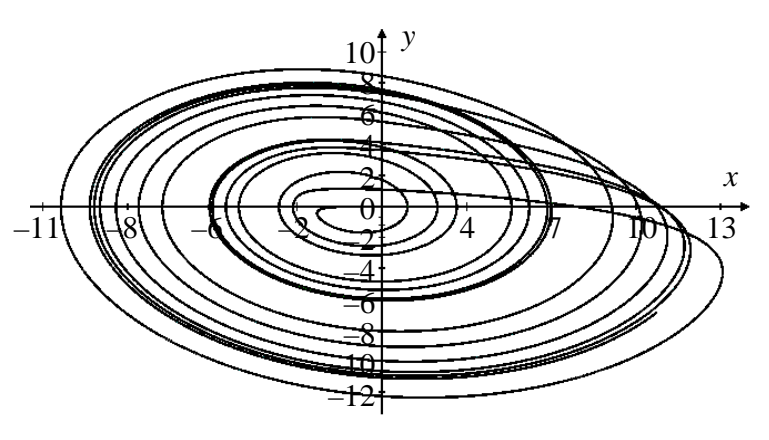

Solution repetition when $\Delta=0.008$, $n_{\max }=10000, \alpha=0.1017$ leads to exactly the same result, that is shown in Fig. 5.
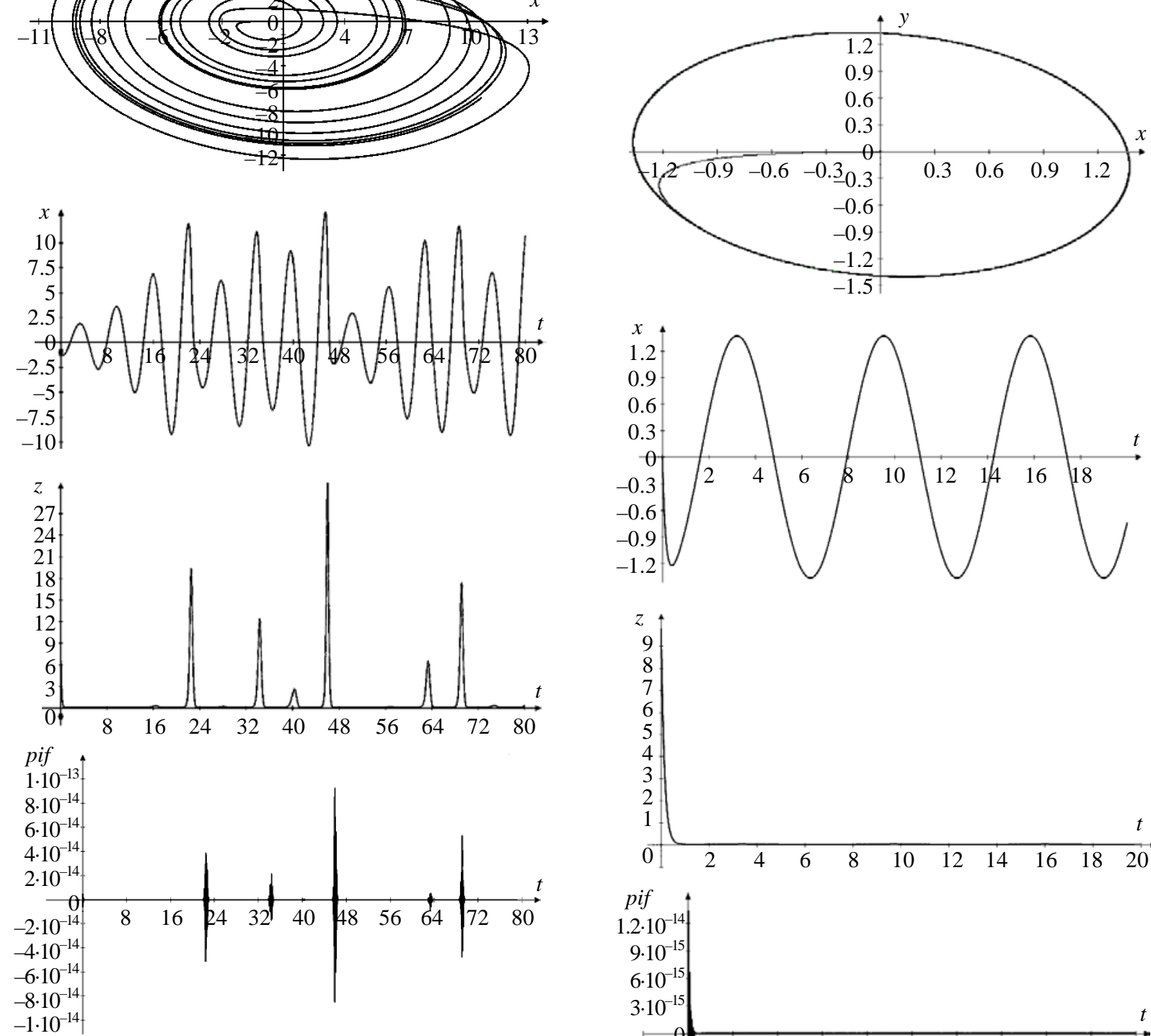

Fig. 4. "Strange attractor", "deterministic chaos" with the following model parameters $e=w=0.2 ; m=6.5 ; \Delta=0.00042$, $n_{\max }=100000, \alpha=0.0979$, pif $=z_{k+1}^{2}-z_{k}^{2}-\left(z_{k+1}-z_{k}\right)\left(z_{k+1}+z_{k}\right)$

Now construct the calculation algorithm (18) with correcting factor $\beta=[1-\Delta \alpha]$ :

$$
\left\{\begin{array}{l}
x_{n+1}=\left[-\left(y_{n}+z_{n}\right) \Delta+x_{n}\right] \beta, \\
y_{n+1}=\left[\left(x_{n}+e y_{n}\right) \Delta+y_{n}\right] \beta, \\
z_{n+1}=\left[w \Delta-m \Delta z_{n}+\Delta x_{n} z_{n}+z_{n}\right] \beta .
\end{array}\right.
$$

Basing on algorithm (19) let us find solution of equation system (18) given the same as in the previous case of options: $e=w=0.2 ; \quad m=6.5$; $\Delta=0.00042, \quad n_{\max }=100000, \quad \alpha=0.0979$, “strange attractor" and "chaos" are not present, the solution leads to steady-state limit cycle.
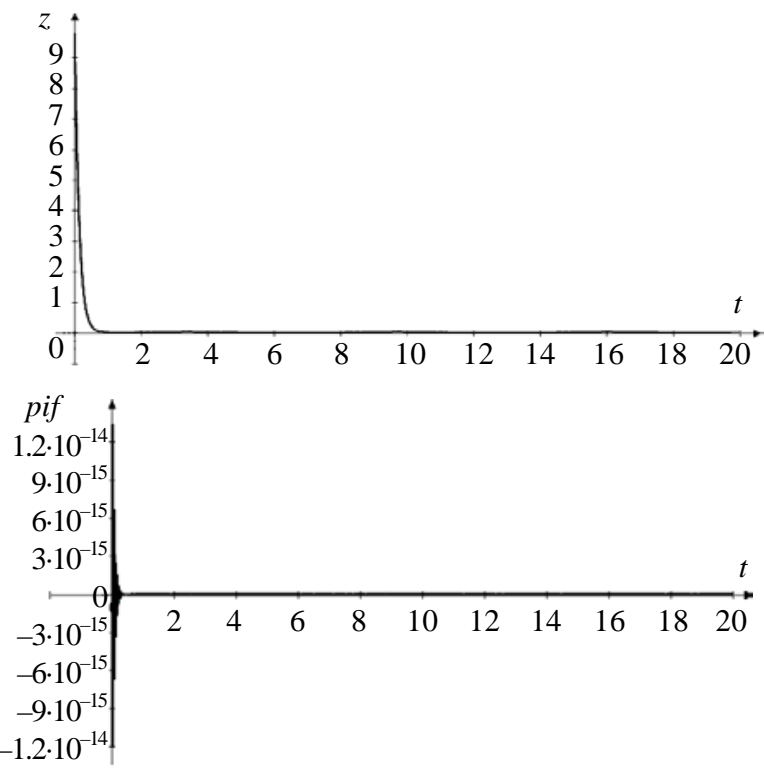

Fig. 5. The exact solution of equation (8) with the following model parameters $e=w=0.2 ; \quad m=6.5 ; \quad \Delta=0.008, \quad n_{\max }=10000$, $\alpha=0.1017$, pif $=z_{k+1}^{2}-z_{k}^{2}-\left(z_{k+1}-z_{k}\right)\left(z_{k+1}+z_{k}\right)$

As can be seen from Fig. 5, pif $=0$ if $t>0.5$, i. e. "numerical noise" is eliminated while forming limit cycle. The system solution (18) gives a stationary attractor in the plane $x, y$. Thus, emergence of "strange attractor" and "deterministic chaos" is the consequence of the exponential calculation error accumulation of poorly determined model equation system. The introduction correcting coefficient $\beta$ eliminates the numerical error and chaos does not 
occur as it should be for a deterministic mathematical model. In real physical system described by model (18) chaos might occur because the system is unstable due to natural noise. But it will not be deterministic, i. e. regenerating chaos, since natural noise cannot be regenerating.

Conclusion. Mathematical physics equations related to poorly determined tasks electrodynamics and nonlinear dynamics can be solved by the listed algorithms with correcting or stabilizing coefficients $\beta$ и $\tau$ in the article.

\section{References}

1. Kurayev A. A. Electrodynamics and radiowaves propagation / A. A. Kurayev, T. L. Popkova, A. K. Sinitsyn. - M.: Infra-m, 2016. $-424 \mathrm{p}$.

2. Samarskii A. A. Difference schemes with operator multipliers / A. A. Samarskii, P. N. Vabishchevich, P. P. Matus // Institute of mathematical modeling of RAS; Institute of mathematics of the NASB. - 1998. - Ser. 442. - P. 64-67.

3. Короновский $A$. A. Методы нелинейной динамики и теории хаоса в задачах электроники сверхвысоких частот: в 2 т. Т. 2. Нестационарные и хаотические процессы / А. А. Короновский, Д. И. Трубецков, А. Е. Храмов. - М.: Физматлит, 2009. - 392 с

4. Kurayev A. A. High-power microwave devices. Analysis methods and parameter optimization / A. A. Kurayev. - M.: Radio and communication, 1986. -208 p.

5. Кураев А. А. Дискретизация и рациональное исчисление в задачах электродинамики / А. А. Кураев, Т. Л. Попкова // Изв. НАН Республики Беларусь. Сер. физ.-техн. наук. 2001. - № 4. - C. 70-76.

6. Rössler O.E. An equation for continuous chaos / O. E. Rössler // Phys. Lett. - 1976. - 57A, N 5. - P. 397-398.

Рукопись поступила 29.06.2016.
А. А. Кураев, В. В. Матвеенко, Т. Л. Попкова

\section{АЛГОРИТМЫ СО СТАБИЛИЗИРУЮЩИМИ КОЭФФИЦИЕНТАМИ ДЛЯ РЕШЕНИЯ ПЛОХО ОБУСЛОВЛЕННЫХ ЗАДАЧ РАДИОФИЗИКИ}

В статье приведены алгоритмы с уточняющими и стабилизирующими коэффициентами, позволяющие получать устойчивые решения систем уравнений, относящихся к плохо обусловленным задачам электродинамики и нелинейной динамики. Продемонстрировано применение модифицированных алгоритмов в задаче распространения $E_{0 i}$-волн в нерегулярном волноводе и модели динамического хаоса Ресслера. В последнем случае показано, что «детерминированный» (т. е. воспроизводимый) хаос невозможен.

Ключевые слова: плохо обусловленная задача, устойчивые численные методы, закритические волны в волноводе, динамический хаос.

О. О. Кураєв, В. В. Матвєєнко, Т. Л. Попкова

$$
\begin{gathered}
\text { АЛГОРИТМИ ЗІ СТАБІЛІЗУЮЧИМИ } \\
\text { КОЕФІЦІЕНТАМИ ДЛЯ РОЗВ'ЯЗАННЯ } \\
\text { ПОГАНО ЗУМОВЛЕНИХ ЗАДАЧ } \\
\text { РАДІОФІЗИКИ }
\end{gathered}
$$

У статті наведено алгоритми з уточнюючими і стабілізуючими коефіцієнтами, що дозволяють отримувати стійкі розв'язки систем рівнянь, що відносяться до погано зумовлених задач електродинаміки та нелінійної динаміки. Продемонстровано застосування модифікованих алгоритмів у задачі поширення $E_{0 i}$-хвиль у нерегулярному хвилеводі та моделі динамічного хаосу Ресслера. В останньому випадку показано, що «детермінований» (тобто відтворений) хаос неможливий.

Ключові слова: погано обумовлена задача, стійкі числові методи, закритичні хвилі у хвилеводі, динамічний хаос. 